\title{
Mortality in Israeli Jewish patients with Type 1 (insulin-dependent) diabetes mellitus diagnosed prior to 18 years of age: a population based study
}

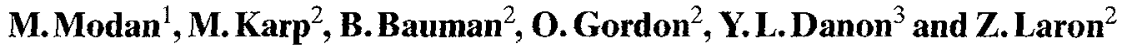 \\ ${ }^{1}$ Department of Clinical Epidemiology, Sheba Medical Center, Tel Hashomer affiliated with the Sackler Faculty of Medicine, Tel Aviv. \\ University and ${ }^{2}$ Institute of Paediatric and Adolescent Endocrinology, Beilinson Medical Center, Petach Tikva, affiliated with the Sackler \\ Faculty of Medicine, Tel-Aviv and ${ }^{3}$ The Israel Defence Forces Medical Corps, Israel
}

Summary. A total of 614 Jewish patients under the age of 18 with Type 1 (insulin-dependent) diabetes mellitus, diagnosed in Israel during the period 1 January 1965 to 31 December 1979, were identified by exhaustive screening of all possible sources. Mortality experience of this cohort was updated to 31 March 1988 through the Central Population Registry and 14 deaths were identified. The ascertainment rate for diagnosed cases as well as for deaths is estimated at about $95 \%$. There was a significantly higher $(p<0.001)$ by 3.2 -fold excess mortality relative to the age and sex-adjusted mortality as expected the general Jewish population in Israel. This excess was due to three cause-of-death categories: diabetic ketoacidosis $(n=3 ; p<0.001)$, cardiovascular diseases $(n=3 ; p<0.001)$ and infections $(n=2 ; p=0.03)$. The rate of malignancies $(n=2)$, external causes $(n=3)$ and other general causes $(n=1)$ did not differ significantly from that expected. During the first 15 years of the disease cumulative mortality resembled that of the general population, with a subsequent steep increase so that by 20 years disease duration, the rate was four-fold higher than expected. This mortality pattern was similar irrespective of age at onset, sex and ethnic group (Ashkenazi vs non-Ashkenazi Jews). A factor contributing to the lack of increase in mortality rate in the first 15 years of Type 1 diabetes may be the comprehensive multidisciplinary treatment approach employed for most juvenile diabetic patients in Israel leading to early referral and an overall better metabolic control.

Key words: Type 1 (insulin-dependent) diabetes mellitus, mortality rate, mortality causes, diabetes duration, population studies.
Patients with Type 1 (insulin-dependent) diabetes mellitus have been found to have an increased mortality rate as compared to the general population [1]. However, there are few studies relating to the magnitude and causes of this excess mortality in diabetes [2-10], and all these were carried out in selected patient groups and not population based cohorts. Only three studies compared the mortality from Type 1 diabetes as a distinct entity to that of the general population [8-10].

The incidence of childhood Type 1 diabetes in Israel is relatively low [11]. The Jewish population in Israel is an immigrant population. The areas from which individuals or their preceding generations immigrated, delineate two major ethnic groups - Ashkenazi (European origin) and non-Ashkenazi (Mediterranean and Mid-Eastern origin), which are genetically and culturally distinct [12]. The main wave of immigration took place in the 1950's, so that the vast majority (over $90 \%$ ) of individuals in the age group of 18 years or less, were born in Israel. Since the incidence of Type 1 diabetes in the population below age 18 is significantly greater by 1.6 fold among Ashkenazi than among
non-Ashkenazi Jews in Israel [11], it was thought to be of interest to compare Type 1 diabetes mortality in the Jewish ethnic groups in Israel. Such comparison could shed light on the differential role that genetic and environmental factors may play in the prognosis of Type 1 diabetes.

This study, which was designed to define the mortality experience of a national cohort of all Type 1 diabetic patients who were diagnosed while under the age of 18 years during a 15-year period and followed-up for 8-23 years, was part of a multinational study [13].

\section{Subjects and methods}

\section{Definition of study cohort}

This investigation was carried out as part of the Diabetes Epidemiology Research International (DERI) study group activities, which is attempting to compare incidence and mortality of Type 1 diabetes in well-defined cohorts in USA (Allegheny county), Finland, Japan 
and Israel [13-15]. The criteria for inclusion in the study was diagnosis of diabetes mellitus, being immediately placed on insulin and being under the age of 18 years during the period 1 January 1965 to 31 December 1979 . Cases of secondary diabetes (e.g. due to corticosteroids, cystic fibrosis or pancreatectomy) were excluded. The study in Israel was confined to the Jewish population only, since completeness of ascertainment of non-Jewish cases was less assured.

The mean Jewish population of Israel under the age of 18 during the mid-study period (1975-1978) was 1,069,000 [16]. Based on a follow-up of about 27,000 individuals of the same age range and during almost the same total study period [17] the rate of immigration over the follow-up period is estimated to be $<5 \%$ (B. Modan et al. unpublished data).

\section{Case ascertainment}

To achieve as complete an ascertainment as possible, all data files in Israel where Type 1 diabetes patients could be listed were screened. The records of the specialized diabetes clinics constituted the primary source of ascertainment. Additional sources were all hospital records in Israel, the list of patients who are members of the Juvenile Diabetes Foundation, and letters sent to all diabetes specialists who were members of the Israeli Diabetes Association, to which 95\% responded. Screening of the army medical files was also carried out since in Israel there is compulsory active army service for both sexes and reserve service up to age 50 for men, and at the age of 17 all citizens have to undergo medical examination with subsequent medical follow-up throughout active and reserve services. Finally, insulin prescriptions of members of Kupat Holim, the Health Insurance Institution of the General Federation of Labor Unions, which covers $85 \%$ of the population were checked. Private practices were not approached since in Israel care of Type 1 diabetes in children and adolescents is almost exclusively in the hands of non-profit health insurance organizations, providing comprehensive care, in which all citizens have to be insured by law.

All records were personally reviewed by two study team members (B. B. \& O. G.). The data obtained from the medical records included: patient identification, ethnic origin, date of diagnosis, date when the first insulin injection was given, the place where diagnosis was made, the place of actual follow-up and development of diabetic complications. Data from all sources were collated to eliminate duplicate cases.

\section{Mortality follow-up}

The cohort mortality experience was updated from 1 January 1965 until 31 March 1988, so that follow-up ranged from 8 to 23 years. Deaths were identified by collating the study file with the Central Population Registry, which has $100 \%$ ascertainment of mortality of people who die in the country. This registry provides information on the place and date of death. The medical records of all the fatal cases were then evaluated for mortality causes. These causes were reviewed in the biannual meetings of the DERI mortality committee (of which M.K. is a member) and the final cause of death was decided upon by agreement to insure standardized definitions. The DERI analyses of the Israeli data [15], for reasons of comparability to the other cohorts, relate only to less than half of the deaths contained in this report (excluding, for each of the two sub-cohorts diagnosed in 1965-1969 and in 1970-1979, the deaths which occurred during the respective period in which they were diagnosed, as well as deaths occurring after 31 December 1984).

\section{Statistical analysis}

Expected number of deaths according to the general population, adjusted for age and sex, total and by cause of death category, were calculated as follows: Age and sex specific mortality rates - total and by cause of death category - for the age range of follow-up (1-34 years) in 5-year age groups, were obtained from the Central Bureau of Statistics $[16,18]$ for the mid follow-up period 1975-1978. This period was selected since data on mortality cross classified by cause of death category and age were available, and rates of total mortality by age, as well as those of total mortality by cause of death category for all ages combined were very close to the mean rates of the total follow-up period. To obtain age and sex adjusted expected rates for the study group these population rates were multiplied by the number of person years contributed by the study cohort to each sex-and 5-year age-group cell, and the number of expected cases in all cells was summed. The expected number of deaths by disease duration was similarly calculated, subdividing the person years in each age group by 5-year duration categories. $95 \%$ confidence limits to the true number of deaths and statistical comparison to the expected number of deaths - total and by cause of death category - were calculated according to the Poisson distribution based on the observed number of deaths [19]. The difference in rate of diabetic complications in subgroups of deaths was done by Fisher's exact test [20]. The cumulative mortality rate from diagnosis of observed and expected cases was estimated by life-table analysis [21]. Comparison of the cumulative mortality curves by age at diagnosis, sex and ethnic group was done by the log-rank test [21]. $95 \%$ confidence limits to the observed 10 and 20 year mortality were calculated by Greenwood's formula [21].

\section{Results}

During the period January 1965-December 1979 614 Type 1 diabetic patients below age 18 were ascertained (Table 1). Of these, $522(85.0 \%$ ) were listed in the files of the specialized diabetes clinics, whereas $41(6.7 \%)$ were found through membership of the Juvenile Diabetes Foundation, and $6(1.0 \%)$ through correspondence with diabetes specialists. Army records contributed 45 cases $(7.3 \%)$ not known from the former sources, 42 of whom were male. No cases which were unlisted in the other sources were found through the hospital records or insulin prescription screening. Place of medical follow-up after diagnosis was in specialized diabetes clinics in $95.4 \%$ (71.7\% hospital and $23.7 \%$ community based) and primary care clinics in $1.5 \%$ and unknown in $3.1 \%$. The sex ratio was $1.03-311$ male and 303 female. Three hundred and thirty patients were of Ashkenazi origin (53\%) and

Table 1. Demographic characteristics of the cohort of all Type 1 (insulin-dependent) diabetic patients in Israel diagnosed below age 18 years during the period January 1965 to December 1979

\begin{tabular}{lll}
\hline & no. & $\%$ \\
\hline Total & 614 & 100.0 \\
Sex: & & \\
$\quad$ Males & 311 & 50.6 \\
$\quad$ Females & 303 & 49.4 \\
Ethnic origin: & & \\
$\quad$ Ashkenazi & 330 & 53.7 \\
$\quad$ Non-Ashkenazi & 284 & 46.3 \\
Age at diagnosis: & & \\
1- 4a & 80 & 13.0 \\
5- 9 & 197 & 32.1 \\
10-14 & 219 & 35.7 \\
15-17 & 118 & 19.2 \\
\hline
\end{tabular}

a No case was diagnosed below the age of 1 year 
284 were of non-Ashkenazi origin (46\%). The age at diagnosis was 1-4 years in 80 patients (no case was diagnosed $<1$ year of age), 5-9 years in 197 patients, 10-14 years in 219 patients and $15-17$ in 118 patients. Mean follow-up was $11.5 \pm 3.1$ years and was practically identical for both sexes as well as for the two ethnic groups. Of this cohort only $22(3.6 \%)$ could not be found in the Central Population Registry due to inaccurate identification data. Among the remaining 592, 14 patients had died by 31 March 1988 (95\% confidence limits 7.65-23.49 cases). Deaths occurred 2 to 22 years after the diagnosis, and age at death ranged from 4 to 34 years. The expected number of deaths according to the total population, adjusted for age and gender, was 4.42 (Table 2). This excess of deaths in the study cohort was highly significant $(p<0.001)$.

Significant ten-fold or more excess of deaths was noted in three cause of death categories - diabetic ketoacidosis $(p<0.001)$, cardiovascular causes $(p<0.01)$ and infections $(p=0.03)$. For the cause categories of malignancies, external causes and other causes the observed and expected numbers were not significantly different. Seven of the deaths had diabetic complications, of which six were among the eight patients in the three cause categories associated with excess mortality, and only one was among the six patients in the other categories. This difference between the two groups of cause categories was statistically significant $(p=0.05)$. No differential patterns of causes of death by age at diagnosis, age at death, sex, ethnic group or disease duration were apparent.

The observed cumulative mortality rates from diagnosis per 1000 , estimated by life-table analysis, as well as the rates expected according to the general population adjusted for age and sex, are shown in Figure 1 and Table 3. The observed ten-year mortality rate was 3.3 (95\% con-

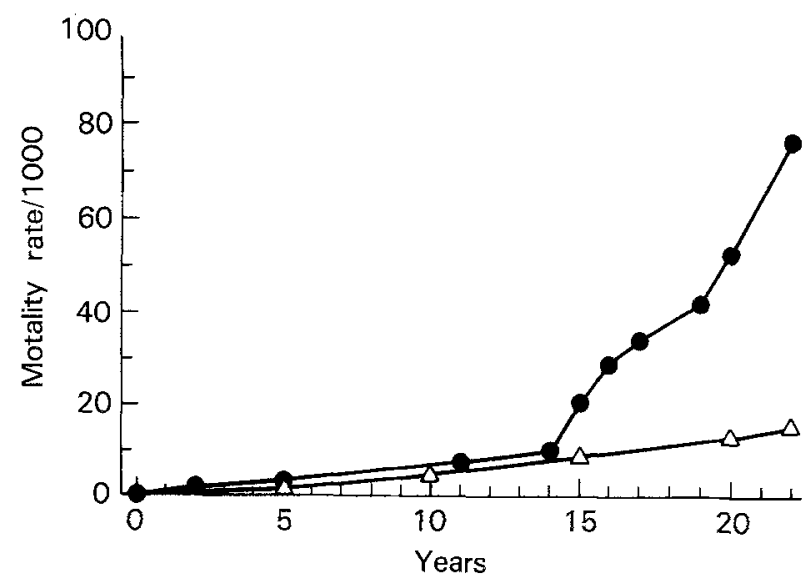

Fig.1. Observed $(\bullet)$ and expected $(\Delta)$ mortality rate per $1000 \mathrm{Jew}$ ish Type 1 (insulin-dependent) diabetic patients in Israel, diagnosed prior to age 18 years by years after diagnosis. Expected rates are according to the general population. The points on the observed curve appear in years in which deaths occurred. The expected rates were calculated by 5 -year interals

fidence limits $0.0-11.6$ ). This was not significantly different from the rate of 4.5 expected in the general population adjusted for age and sex. At the 15 th year after diagnosis, mortality began to rise steeply so that at 20 years' duration of diabetes the observed cumulative mortality rate observed was 52.3 (19.6-86.0). This rate exceeded that expected 4.1-fold, and the difference was highly significant $(p<0.001)$.

No significant differences in the cumulative mortality patterns were observed between categories according to sex, ethnic group, age or time period at diagnosis (data not shown). Thus, the only factor significantly affecting mor-

Table 2. Clinical data of the 14 fatal cases of Jewish patients with Type 1 (insulin-dependent) diabetes mellitus in Israel (January 1965 March 1988), and age-sex adjusted expected number of fatalities based on the Israeli background population by cause of death category

\begin{tabular}{|c|c|c|c|c|c|c|c|c|c|c|c|c|}
\hline \multicolumn{2}{|l|}{ Cause of death } & \multirow[t]{2}{*}{ Sex } & \multirow{2}{*}{$\begin{array}{l}\text { Ethnic } \\
\text { origin }\end{array}$} & \multicolumn{2}{|l|}{ Age at: } & \multirow{2}{*}{$\begin{array}{l}\text { Disease } \\
\text { duration } \\
\text { (years) }\end{array}$} & \multicolumn{3}{|c|}{ Diabetic complications: } & \multicolumn{2}{|c|}{ No. cases per cause category: } & \multirow[t]{2}{*}{$p$} \\
\hline Category & Specific & & & Onset & Death & & $\begin{array}{l}\text { Nephro- } \\
\text { pathy }\end{array}$ & $\begin{array}{l}\text { Retino- } \\
\text { pathy }\end{array}$ & $\begin{array}{l}\text { Neuro- } \\
\text { pathy }\end{array}$ & Observed $^{\mathrm{a}}$ & Expected & \\
\hline Diabetes mellitus & Diabetic ketoacidosis & $\begin{array}{l}\mathrm{F} \\
\mathrm{F} \\
\mathrm{M}\end{array}$ & $\begin{array}{r}\text { A } \\
\text { A } \\
\text { NA }\end{array}$ & $\begin{array}{r}5 \\
13 \\
14\end{array}$ & $\begin{array}{l}19 \\
29 \\
29\end{array}$ & $\begin{array}{l}14 \\
16 \\
15\end{array}$ & $\begin{array}{l}- \\
+ \\
-\end{array}$ & $\begin{array}{l}- \\
+ \\
+\end{array}$ & $\begin{array}{l}- \\
+ \\
+\end{array}$ & $3(0.62-8.76)$ & 0.02 & $<0.001$ \\
\hline Cardiovascular & $\begin{array}{l}\text { CVA } \\
\text { Cardiomyopathy }\end{array}$ & $\begin{array}{l}F \\
F \\
M\end{array}$ & $\begin{array}{r}\mathrm{A} \\
\mathrm{A} \\
\mathrm{NA}\end{array}$ & $\begin{array}{r}10 \\
18 \\
5\end{array}$ & $\begin{array}{l}21 \\
34 \\
20\end{array}$ & $\begin{array}{l}11 \\
16 \\
15\end{array}$ & $\begin{array}{l}+ \\
+ \\
-\end{array}$ & $\begin{array}{l}+ \\
+ \\
-\end{array}$ & $\begin{array}{l}- \\
- \\
-\end{array}$ & $3(0.62-8.76)$ & 0.17 & $<0.001$ \\
\hline Infections & $\begin{array}{l}\text { Septicaemia (NF) } \\
\text { Peritonitis (PD) }\end{array}$ & $\begin{array}{l}\mathrm{M} \\
\mathrm{F}\end{array}$ & $\begin{array}{c}\text { NA } \\
\text { A }\end{array}$ & $\begin{array}{r}8 \\
12\end{array}$ & $\begin{array}{l}28 \\
34\end{array}$ & $\begin{array}{l}20 \\
22\end{array}$ & $\begin{array}{l}+ \\
+\end{array}$ & $\begin{array}{l}+ \\
+\end{array}$ & $\begin{array}{l}+ \\
-\end{array}$ & $2(0.24-7.22)$ & 0.17 & 0.03 \\
\hline Malignancies & $\begin{array}{l}\text { Leukaemia } \\
\text { Carcinoma of lung }\end{array}$ & $\begin{array}{l}\mathrm{M} \\
\mathrm{F}\end{array}$ & $\begin{array}{l}\mathrm{A} \\
\mathrm{A}\end{array}$ & $\begin{array}{r}2 \\
12\end{array}$ & $\begin{array}{r}4 \\
29\end{array}$ & $\begin{array}{r}2 \\
17\end{array}$ & $\begin{array}{l}- \\
-\end{array}$ & $\begin{array}{l}- \\
-\end{array}$ & $\begin{array}{l}- \\
-\end{array}$ & $2(0.24-7.22)$ & 0.64 & NS \\
\hline External causes & $\begin{array}{l}\text { RTA } \\
\text { Murder }\end{array}$ & $\begin{array}{l}\mathrm{M} \\
\mathrm{M} \\
\mathrm{M}\end{array}$ & $\begin{array}{c}\text { NA } \\
\text { A } \\
\text { NA }\end{array}$ & $\begin{array}{r}8 \\
15 \\
6\end{array}$ & $\begin{array}{l}23 \\
20 \\
17\end{array}$ & $\begin{array}{r}15 \\
5 \\
11\end{array}$ & $\begin{array}{l}- \\
- \\
-\end{array}$ & $\begin{array}{l}- \\
- \\
-\end{array}$ & $\begin{array}{l}- \\
- \\
-\end{array}$ & $3(0.24-7.22)$ & 2.28 & NS \\
\hline All causes & & & & & & & & & & $14(7.65-23.49)$ & 4.42 & $<0.001$ \\
\hline
\end{tabular}

$\mathrm{F}=$ female $\mathrm{M}=$ male $\mathrm{A}=$ Ashkenazi, $\mathrm{NA}=$ non-Ashkenazi, $\mathrm{NS}=$ not significant, + or $-=$ presence or absence of complications; $\mathrm{NF}=$ necrotizing fascia, $\mathrm{PD}=$ peritoneal dialysis, $\mathrm{RTA}=$ Road traffic accident, $\mathrm{CVA}=$ cerebrovascular accident

a $95 \%$ confidence limits for true number of deaths appear in parentheses 
Table 3. Observed and expected mortality rate per 1000 patients 10-20 years after diagnosis of Type 1 (insulin-dependent) diabetes mellitus. Expected rate is according to the general population

\begin{tabular}{lcc}
\hline & 10 year & 20 year \\
\hline Expected rate & 4.5 & 12.9 \\
Observed rate & 3.3 & 52.3 \\
(95\% confidence limits) & $(0.0-11.6)$ & $(19.6-85.0)$ \\
Standardized mortality ratio & 0.7 & 4.1 \\
$p$ & $\mathrm{NS}$ & $<0.001$ \\
\hline
\end{tabular}

tality during the first 20 years of Type 1 diabetes, in cases diagnosed prior to 18 years of age in our cohort was a disease duration longer than 15 years.

\section{Discussion}

There have only been three previous studies of cohorts of diabetic patients comparing their mortality experience to that of the general population in which Type 1 diabetes was addressed as a distinct entity [8-10], and comparisons to our study will be confined to them. Of these, two cohorts were from Denmark $[9,10]$, and one from Pittsburgh [8] and all were selected since the subjects studied comprised either patients under treatment in a referral centre [8-10], or those detected in a prevalence study [9]. Our study is thus the first mortality follow-up of Type 1 diabetic patients diagnosed during a specified time period which is based on a complete national registry of cases and deaths, accomplished by reviewing an exhaustive list of sources of ascertainment.

Israel offers an unique opportunity for establishing well-defined national cohorts of patients. The country is small, with a relatively stable population, all of whom are listed in the Central Population Registry with mortality ascertainment of practically $100 \%$. Comprehensive modern socialized medical services of adequate standards are freely available at all socioeconomic levels even in remote areas. There is an extensive network of "reach-out" for detecting health problems in children through mother and child care centres and schools. Private practice regarding childhood and adolescent diabetic patients is practically non-existent. Parents prefer the free treatment in specialized diabetic clinics which are part of the health care system and are mostly hospital based, with comprehensive sophisticated ancillary clinical and laboratory services, which are not available in private facilities. Finally, all citizens at the age of 17 undergo a pre-enlistment medical examination in the army, and all problems and diagnoses are recorded whether the subject is exempt from service or not. These records are kept for the period of eligibility for active and reserve service and are thus available short-term for both sexes and long-term for men.

The primary sources of ascertainment of Type 1 diabetic patients in our study, were the specialized diabetic clinics. Secondary sources were army and hospital records, insulin prescriptions of Kupat Holim, the registry of the Juvenile Diabetes Foundation and information from $95 \%$ of all diabetes specialists in Israel. Based on the methods described above, it is estimated that the degree of ascertainment in this study is about $95 \%$. This estimate is based on the fact that we found 42 men but only 3 women in the army records who were not listed elsewhere. Practically all of these unlisted cases were under treatment in the various diabetes clinics which were screened, and were distributed among these clinics in proportion to their size and thus apparently represent occasionally missed records. Since the sex ratio in our cohort is about 1:1, and all our men were in the age range eligible for active and reserve service, hypothetically about 40 women might have been missed. As no new cases were found in the screening of the insulin prescriptions, it seems unlikely that more than a few other cases were unlisted in any of the other sources. As for deaths, our cohort was linked to the Central Population Registry enabling us to detect all fatal cases. Only $3.6 \%$ of the cases could not be located in the Central Population Registry, and the potential proportion of deaths unidentified due to this factor is bound to be smaller since most of the deaths were known already from the clinic records. While deaths among cases who emigrated from the country are not recorded, the population rate of immigration in the age range of our cohort is less than $5 \%$. Thus, the ascertainment rate of deaths in our study is about $95 \%$.

As in all other studies [8-10] we found considerable excess mortality compared to the general population after adjustment for age and sex. This excess was due to diabetic ketoacidosis, cardiovascular disease and infections. Mortality from malignancies, external causes and other general causes resembled that of the general population. These trends seem corroborated by the fact that among deaths due to causes which were in excess of those expected from the general population, the rate of those from diabetic complications was significantly higher as compared to deaths from other causes. In the Pittsburgh study [8] also, excess mortality was due to diabetic ketoacidosis and cardiovascular disease, with no excess of neoplasms and external or other general causes. However, diabetic nephropathy was a major cause of death in that study while in our study it was not. Infections as a cause of death were not examined separately in the Pittsburgh study, but diabetic patients are considered to be more susceptible to infections. The Danish studies did not relate to this issue.

Of particular interest is our finding of no difference in mortality rate between the Type 1 diabetic patients and the general population in the first 15 years of disease, irrespective of age at onset, age at death, sex or ethnic group. It is noteworthy that in the Pittsburgh study [8], the only other study which presented life-table analysis, the pattern of mortality was similar to ours in that rates were relatively low in the first 15 years of the disease with a sharp increase later (Table 4). However, their rates after the first 10 years of disease during a comparable time-period were considerably higher than ours -14 of 1000 as opposed to 3 of 1000 respectively. Data for $\geq 15$ years of duration were available only for the period $\leq 1965$, characterized by higher mortality rates in the Pittsburgh as well as in the Danish studies [8-10]. In the Pittsburgh study the expected mortality according to the general population was 
Table 4. Comparison of cumulative mortality rate per 1000 by duration in our data to the Pittsburgh Study

\begin{tabular}{|c|c|c|c|}
\hline \multirow{3}{*}{$\begin{array}{l}\text { Duration } \\
\text { (years) }\end{array}$} & \multirow{2}{*}{$\begin{array}{l}\text { Israel }^{a} \\
1965-1979 \\
n=614\end{array}$} & \multicolumn{2}{|c|}{ Pittsburgh $(8)^{\mathrm{b}}$} \\
\hline & & $\begin{array}{l}1950-1965 \\
n=764\end{array}$ & $\begin{array}{l}1966-1971 \\
n=423\end{array}$ \\
\hline & Rate & \multicolumn{2}{|c|}{ Rate } \\
\hline$\leq 1$ & 0 & 12 & 5 \\
\hline$\leq 5$ & 3 & 24 & 7 \\
\hline$\leq 10$ & 3 & 38 & 14 \\
\hline$\leq 15$ & 11 & 56 & - \\
\hline$\leq 20$ & 52 & 135 & - \\
\hline
\end{tabular}

a The 10-year mortality was equal to the 5-year mortality since no additional deaths occurred until the 11 th year; ${ }^{b}$ Rates for the study period 1950-1965 were re-calculated from Table 4 in that study. Rates for the period 1966-1971 were given only for duration $\leq 10$ years

not calculated by duration as in our study. However, as age-specific population mortality rates in the USA and Israel are of the same order of magnitude, it seems that the mortality rates during the period after 1965 in that study exceeded those of the general population, even in the first 10 years of the disease. The potential patient selection in the Pittsburgh study, as well as genetic and environmental factors, could play a role in the low mortality in the first 15 years of the disease in our cohort. However, it could also be ascribed to the structure of the primary care system in Israel which promotes early detection of cases and quick referral to specialized clinics and to the centralized multidisciplinary and comprehensive therapeutic approach [22].

The steep increase in mortality rates 15 years after diagnosis found in our study, the Pittsburgh study and one of the Danish studies [10], is unlike the gradual increase in comparable ages in the general population and indicates a strong effect of duration of disease. This consistent steep increase in mortality after 15 years of disease duration is intriguing. It may reflect the fact that completely satisfactory control over very long periods of time is a goal yet to be realized, perhaps due to less adequate treatment in adulthood resulting from poorer patient compliance and/or lower attention by the physicians. However, it may also reflect natural pathophysiological processes, the identification of which could further our understanding of how to improve prognosis.

While no significant effect of sex, ethnic group, age at diagnosis, age at death or period of diagnosis on mortality were found in our study, the small number of deaths allows us to conclude only that their effect is weaker than that of duration, at least in the age range of follow-up in our study which was up to 34 years. By the same token, the effect of these factors on causes of death could not be meaningfully evaluated. On the other hand, the conclusions regarding the similarity to the general population in terms of total mortality during the first 15 years of the disease and steep increase later are valid, as evidenced by the $95 \%$ confidence limits based on the observed rates. The validity is underscored by the complete ascertainment of cases and deaths for the whole country.

We believe that these data suggest that mortality in Type 1 diabetes can be considerably reduced to resemble that of the general population by improved quality and comprehensiveness of the initial and follow-up therapeutic regimen and high standards of metabolic control throughout the years.

Acknowledgements. We acknowledge with gratitude our indebtedness to the following: Dr. R.E.LaPorte, Pittsburgh University School of Public Health, Director and Coordinator of the DERI Study Group, and to Dr. T.J.Orchard, Pittsburgh University, Diabetes Research Center, Head of the Mortality Classification Committee.

The following hospitals and clinics in Israel we thank for their co-operation during assembly of the data:

Kupat Holim Hospitals: Dr. Y. Rosezki, Beilinson Medical Center, Dr. Z.Cnaani, Dr. R. Koslowski, Kaplan Hospital, Prof. S. Weizman, Dr. E. Lieberman, Soroka Medical Center, Dr. O.Loboshitzky, Haemek Hospital, Dr. M.Shapira, Dr. H.Hirsch, Meier Hospital, Dr. H.Hirsh, Shaareh Zedek Hospital, Dr. B.Dreznin, Hasharon Hospital.

Government Hospitals: Dr. I.Ser, Dr. A.Rubinstein, Ichilov Medical Center; Dr. I. Ritterman, Rokach Medical Center; Prof. J.Sack, Dr. R. Theodor, Sheba Medical Center; Dr. D. Fried, Dr. A. Hanukuglu, Wolfsson Hospital; Prof. Y.Gilboa, Dr. T. Rosenberg, Assaf Harofe Hospital; Dr. Y. Kanter, Dr. P. Vardi, Rambam Medical Center; Dr. T. Hershkowitz, Naharia Hospital; Dr. S.H.Pollack, Barzilai Hospital; Dr. S. Ben-Asulin, Poriah Hospital, and Hillel Jaffe Hospital; Rothschild Hospital and Ziv Hospital.

Hadassah Medical Center: Prof. E. Cerasi, Prof. H. Bar-On, Dr. I. Raz, Dr. B. Glazer.

Kupat Holim Diabetes Clinics: Ms. B.Prazin, Dr. I.Stern, Dr. B.Schindel, Dr. S. Altman, Dr. A. Rabina, Dr. O. Minuchin, Dr. J. Arad, Dr. Z. Loevinger, Dr. C. Norimberg.

Other clinics: Prof. A. Goldschmidt, Dr. R. Gurewitz, Dr. H. Gutman.

To Dr. B. Korenbrot, Israeli Defence Forces, Medical Corps.

The study was supported by a grant from the NIH - National Institute of Diabetes and Digestive and Kidney Diseases, No. 5 RO1 DK3905-04.

\section{References}

1. Panzram G (1984) Epidemiology data on excess mortality and life expectancy in insulin dependent diabetes mellitus - critical review. Exp Clin Endocrinol 83: 93-100

2. Knowles HC Jr, Guest GM, Lampe J, Kessler M, Skillman TH (1965) The course of juvenile diabetes treated with an unmeasured diet. Diabetes 14:239-273

3. Sultz HA, Schlesiger ER, Mosher WE, Feldman JG (1972) Childhood diabetes mellitus. Long-term childhood illness. University of Pittsburgh Press, Pittsburgh, pp 223-248

4. Deckert T, Poulsen JE, Larsen M (1978) Prognosis of diabetics with diabetes onset before age of thirty-one. Diabetologia 14: 363-377

5. Lestradet H, Papoz L, Hellouin de Menibus C, Levavasseur F, Besse J, Billaud L, Battistell F, Tric PH, Lestradet F (1981) Longterm study of mortality and vascular complications of juvenile onset (type I) diabetes. Diabetes 30: 175-179

6. Christlieb AR, Warram JH, Krolewski AS, Busick EJ, Ganda OP, Asmal AC, Soeldner JS, Bradley RF (1981) Hypertension. The major risk factor in juvenile-onset insulin dependent diabetes. Diabetes 30: 90-96

7. Green A, Hougaard P (1984) Epidemiological studies of diabetes mellitus in Denmark: 5. Mortality and causes of death among insulin-treated diabetic patients. Diabetologia 26: 190194

8. Dorman JS, Laporte RE, Kuller LH, Cruickshanks KJ, Orchard TJ, Wagener DK, Becker DJ, Cavender DE, Drash AL (1984) 
The Pittsburgh insulin dependent diabetes mellitus (IDDM) morbidity and mortality study. Mortality results. Diabetes 33: 271-276

9. Green A, Borch-Johnsen K, Andersen PK, Hougaard P, Keiding N, Kreiner S, Deckert T (1985) Relative mortality of Type 1 (insulin-dependent) diabetes in Denmark: 1933-1981. Diabetologia $28: 339-342$

10. Borch-Johnsen K, Kreiner S, Deckert T (1986) Mortality of Type 1 (insulin-dependent) diabetes mellitus in Denmark: A study of relative mortality in 2930 Danish Type 1 diabetic patients diagnosed from 1933 to 1972 . Diabetologia 29: 767772

11. Laron Z, Karp M, Modan M (1985) The incidence of insulin dependent diabetes in Israeli children and adolescents $0-20$ years of age: A retrospective study 1975-1980. Diabetes Care 8 [Suppl 1]: 24-28

12. Goodman RM, Motulsky AG (eds) (1979) Genetic diseases among Ashkenazi Jews. Raven Press, New York

13. Diabetes Epidemiology Research International Group (1988) Geographic patterns of childhood insulin-dependent diabetes mellitus. Diabetes 37:1113-1119

14. Bauman B, Gordon O, Karp M, Modan M, Laron Z (1988) Twenty years IDDM mortality follow-up in Israel. Diabetes Epidemiology Research International Study Group. Diabetes 38 [Suppl 2]: 149A (Abstract)

15. Diabetes Epidemiology Research International Study Group (1988) Cause specific mortality IDDM. Diabetes 38 [Suppl 2]: 145A (Abstract)
16. Statistical abstracts of Israel nos. 26-30, Central Bureau of Statistics, Government Press, Jerusalem

17. Modan B, Ron E, Chetrit A, Alfandary E, Boice JD Jr, Katz L (1989) Increased risk of breast cancer following low dose irradiation. Lancet I: 629-631

18. Causes of Death 1978 (1980) Special series No. 638. Central Bureau of Statistics, Government Press, Jerusalem

19. Diem K, Seldrup J (1982) Introduction to Statistics, Statistical Tables, Mathematical Formulae. In: Lentner C(ed) Geigy Scientific Tables. 8th edn, Vol 2. Ciba Geigy, Basel, p 152

20. Maxwell AE (1961) Analyzing qualitative data. John Wiley and Sons, pp 23-26

21. Kahn HA (1983) An introduction to epidemiologic methods. Oxford University Press, New York, pp 121-145

22. Laron Z, Galatzer A, Amir S, Gil R, Karp M, Mimouni M (1979) A multidisciplinary comprehensive ambulatory treatment scheme for diabetes mellitus in children. Diab Care 2: 342-348

Received: 12 September 1990

and in revised form: 25 March 1991

Dr. M. Modan

Head, Biometry Unit

Department of Clinical Epidemiology

Chaim Sheba Medical Center

Tel Hashomer, 52621

Israel 